\title{
Strategic Business Management: A Practical Framework and Causal Model of Empowering Leadership, Team Cohesion, Knowledge-Sharing Behavior, and Team Performance
}

\author{
Kijpokin Kasemsap \\ Suan Sunandha Rajabhat University, Bangkok, Thailand \\ kijpokinkasemsap@yahoo.com
}

\begin{abstract}
Research objectives were to determine a practical framework and to create a causal model of empowering leadership, team cohesion, knowledge-sharing behavior, and team performance of petroleum refinery plant employees in Thailand. The study reported the responses of 594 operational employees from seven petroleum refinery plants operating in different parts of Thailand. Data were analyzed with descriptive statistics using SPSS (version 11.5) and path analysis using LISREL (version 8). Research findings indicate that dimensions of empowering leadership, team cohesion, and knowledge-sharing behavior have mediated positive effect on team performance. Knowledge-sharing behavior positively mediates the relationships between empowering leadership and team performance and between team cohesion and team performance. Furthermore, empowering leadership is positively correlated with team cohesion.
\end{abstract}

Keywords: Causal Model, Empowering Leadership, Knowledge-Sharing Behavior, Team Cohesion, Team Performance

\section{Introduction}

Today's economy has shown the importance of knowledge and intellectual capital to organizations. Current trends have given birth to new concepts such as knowledge map (Robertson, 2002). Knowledge sharing is regarded as the informal communication process involving the sharing of knowledge between co-workers (Siemsen et al., 2008). In order to gain a competitive advantage, organizations tend to leverage their knowledge-related competencies (Kankanhalli et al., 2005). Continuous knowledge management (KM) can promote organizational innovation and play a key role in the organizational success (Nonaka \& Takeuchi, 1995). In addition, problems such as maintaining, locating and applying knowledge have intensified the importance of organizational knowledge management (Alavi \& Leidner, 2001). Furthermore, knowledge sharing has been of benefit to both individuals and groups (Reid, 2003). In considering leadership approaches, the study has highlighted the importance of leaders' behaviors for team performance (Druskat \& Wheeler, 2003). The conceptualization of empowering leadership involves highlighting significance of work, thus providing participation in decision making, conveying confidence in performance, and removing bureaucratic contraints (Ahearne et al., 2005). Katzenbach and Smith (1993) stated that there are basic differences between group and team. A team is small group of people generating positive synergy through coordinated effort and with complementary skills committed to a common purpose (Katzenbach \& Smith, 1993). Team members hold themselves mutually accountable for accomplishing a shared goal (Katzenbach \& Smith, 1993). A group discovers its own strength by coming together and helping each individual perform within his or her area of responsibility (Katzenbach \& Smith, 1993). Research objectives were to determine a practical framework and to create a causal model of empowering leadership, team cohesion, knowledge-sharing behavior, and team performance of petroleum refinery plant employees in Thailand.

\section{Review of Literature}

Team performance is defined as the extent to which a team accomplishes its goal or mission (Devine \& Phillips, 2001). Team performance may be evaluated qualitatively or quantitatively according to substantive work outcome. Empowering teams with requisite authority and responsibility appear to be an important factor for successful teams (Mathieu et al., 2006). The relationship between leadership behaviors and performance of management teams is more complicated than simple enactment of behaviors (Mathieu et al., 2006). Behavioral integration is a construct encompassing interrelated tasks and social dimensions that collectively capture the degree to which a team engages in mutual and collective interaction (Simsek et al., 2005). The role of knowledge sharing as team process and team cohesion as an emergent state has been considered in the empowering leadership-performance 
relationship (Barrick et al., 2007). Team processes are emphasized differently from emergent states (Marks et al., 2001). The former is the means by which individual members interact to utilize various resources, whereas the latter is the means by which individual members describe cognitive, motivational, and affective states of teams (Marks et al., 2001). Knowledge sharing is a team process as team members sharing task-relevant ideas, information, and suggestions with one another (Srivastava et al., 2006). Team cohesion is an emergent state that reflects the shared commitment, attraction, and team pride emerging from experiences and interactions among team members influencing the execution of subsequent teamwork processes and outcomes (Beal et al., 2003). Knowledge sharing refers to the provision of task information and know-how to collaborate with others to solve problems, develop new ideas, or implement policies or procedures (Cummings, 2004).

Knowledge sharing contributes to the creation and utilization of knowledge, and has an important role in the process of knowledge management (Cummings, 2004). Although knowledge management is composed of knowledge adoption, knowledge coding, knowledge storage, knowledge sharing, and knowledge utilization, knowledge sharing is the most important aspect (Cummings, 2004). Sufficient knowledge sharing causes organizational members to gather knowledge more conveniently and rapidly, organizational members recreate and use knowledge by sharing knowledge to enhance knowledge management performance (Cummings, 2004). Knowledge sharing can facilitate organizational innovation, core capability (Gold et al., 2001), and competitive advantage (Teece, 1998). Knowledge creation typically occurs through the exchange and integration of knowledge elements (Nahapiet \& Ghoshal, 1998). Peccei and Rosenthal (2001) stated that work autonomy and service ability have a positive impact on service performance. Empowering leadership is viewed as a process of implementing conditions that enable sharing power with an employee by delineating the significance of employee's job, thus providing greater decision-making autonomy, expressing confidence in employee's capabilities, and removing hindrances to performance (Ahearne et al., 2005; Zhang \& Bartol, 2010). The empowered employee can be self-managed to reach a higher psychological cognition (Ahearne et al., 2005; Zhang \& Bartol, 2010). Participative decision-making and coaching behaviors of the empowering leader also ensure team members receiving fair recognition for their contributions of ideas and information, and provide them with more opportunities to share their knowledge (Srivastava et al., 2006). Empowering leadership further encourages team members to solve problems together, thereby providing opportunities for knowledge exchanges (Arnold et al., 2000).

Srivastava et al. (2006) found that empowering leadership fosters knowledge sharing among team members. A comprehensive consideration of alternatives and a better utilization of existing knowledge lead to the increased knowledge sharing within a team, resulting in improved decision making (Stasser \& Titus, 1985). Knowledge sharing in the formation of shared mental models enables task execution and beneficial effect on team coordination and achieves higher team performance. Smith-Jentsch et al. (2005) stated that there are the positive effects of shared mental models on team performance. Cohesiveness is an attractive feature of teams (Amabile et al., 2004; Littlepage et al., 1989). Highly cohesive team members are committed to team goals and activities, reflecting that cohesiveness is instrumental in affective dimension as manifested in most teams (Amabile et al., 2004; Littlepage et al., 1989). Two fundamental aspects of cohesion are task cohesion and social cohesion (Carron et al., 1985). Social cohesion is emphasized on relationships within the group (Carron et al., 1985). Task cohesion is emphasized on collective performance, goals, and objectives (Carron et al., 1985). In general, leaders see themselves competent and are able to influence team cohesion and work environment in meaningful ways (Sigler \& Pearson, 2000). Leaders are also able to identify and prevent any threat to group cohesion (Yalom, 2005). Thus, the style and experience of the leaders have impact on group cohesion (Antonuccio et al., 1997; Littlepage et al., 1989; Yalom, 1995). For instance, it is clear that a higher team cohesion will deeply affected by the behaviors of leaders such as delegating authority to the team member (Amabile et al., 2004), expressing confidence in the member's capabilities (Littlepage et al., 1989) using positive feedback technique (Antonuccio et al., 1987) and delineating the significance of member's job (Zhang \& Bartol, 2010).

Furthermore, the members of a cohesive team exhibit higher levels of affinity and trust in one another with higher levels of satisfaction and affective attraction to the team (O'Reilly et al., 1989). Elron (1997) concluded that cohesion of management team contributes to team performance on issues such as implementation of decisions and strategies, comprehensive vision, and goals. There appears to be an important linkage between employees' positions in a network of positive interpersonal interactions and their satisfaction (Shaw, 1981) and attraction to the team (Lawler et al., 2000). Gully et al. (1995) stated 
that performance is higher when teams are highly cohesive. Empowering leadership is likely to be beneficial for team performance because of high degree of wholeness, unity of effort, and great emphasis on group cohesiveness among members who work cooperatively as a team (Beal et al., 2003; Keller, 1986). Team climate is a composite construct consisting of three dimensions, namely affiliation, trust, and innovation (Bock et al., 2005). Affiliation, equivalent to cohesion in nature, refers to the perception of a sense of togetherness among members (Hogg, 1992). Cohesion, defined as members' attraction to the team (Hogg, 1992), can be considered as a psychological force that binds people together (Keyton \& Springston, 1990). Trust in the team environment is defined as a member's willingness to accept vulnerability based on a confident expectation of teammates' competence, integrity, and benevolence (Pavlou et al., 2007). Liang et al. (2007) stated that team climate significantly influences individuals' perceptions, normative beliefs, and technology usage. The sense of affiliation or cohesion tends to enhance team members' willingness to care for or help one another so that team members are more likely to share knowledge with one another (Liang et al., 2007).

\section{Methodology}

Data for this study were collected from 594 operational employees out of 11,725 operational employees working in the seven petroleum refinery plants in Thailand by using Yamane's formula (Yamane, 1970) for a $96 \%$ confidence level with a $4 \%$ margin of error by the proportional random sampling method. All the constructs were operationalized based on a seven - point Likert scale ranging from 1 (strongly disagree) to 7 (strongly agree). Data were analyzed with descriptive statistics using SPSS (version 11.5) and assessed with confirmatory factor analysis (CFA) to confirm the heterogeneity of all constructs and path analysis (Joreskog \& Sorborn, 1993) to detect the cause-effect relationships among various dimensions of main constructs of the study using LISREL (version 8) on a structured questionnaire containing standard scales of empowering leadership, team cohesion, knowledge-sharing behavior, and team performance, besides some demographic details like age, education, and tenure with the organization. Empowering leadership was measured using the 12-item scale questionnaire developed by Ahearne et al. (2005) comprising four factors, namely fostering participation in decision making, expressing confidence in high performance, enhancing the meaningfulness of work, and providing autonomy from bureaucratic constraints. Team cohesion was measured using the eight-item scale questionnaire developed by Carron and Brawley (2000) and Carron et al. (1985) comprising two elements of task cohesion and social cohesion. Knowledge-sharing behavior was measured using the 13-item scale questionnaire developed by Senge (1997) comprising three factors, namely organizational knowledge, task knowledge, and interpersonal knowledge. Team performance was measured using the five-item scale questionnaire developed by Amy (1999). Examples of team performance items are, "This team meets or exceeds its objectives" and "This team's work is of high quality".

\section{Results and Discussion}

A practical framework and a causal model are created. Research findings indicated that dimensions of empowering leadership, team cohesion, and knowledge-sharing behavior have mediated positive effect on team performance. Knowledge-sharing behavior positively mediates the relationships between empowering leadership and team performance and between team cohesion and team performance. Furthermore, empowering leadership is positively correlated with team cohesion.

Figure 1: Practical Framework and Causal Model.

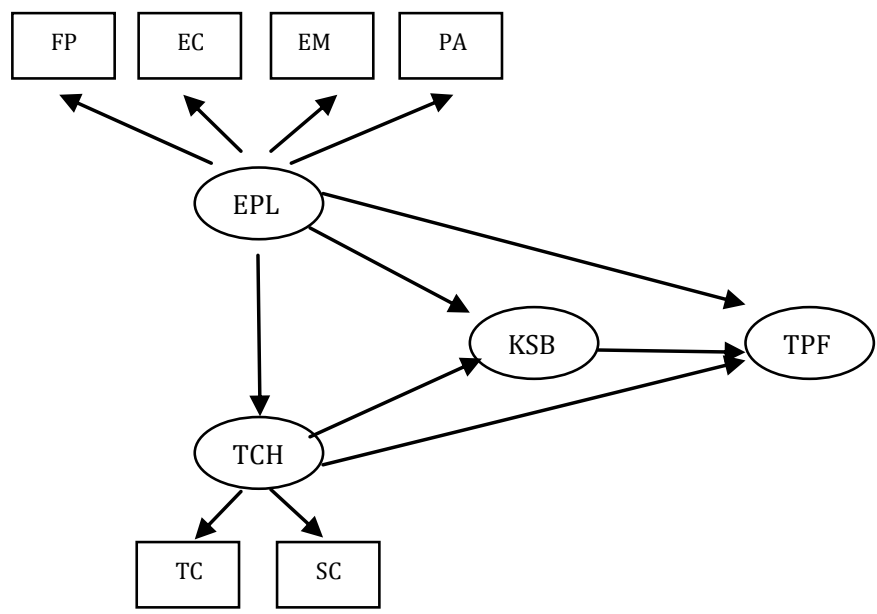


Key: $\mathrm{EPL}=$ Empowering Leadership, FP = Fostering Participation in Decision Making, EC = Expressing Confidence in High Performance, EM = Enhancing the Meaningfulness of Work, PA = Providing Autonomy from Bureaucratic Constraints, $\mathrm{TCH}=$ Team Cohesion, $\mathrm{TC}=$ Task Cohesion, $\mathrm{SC}=$ Social Cohesion, $\mathrm{KSB}=$ Knowledge-Sharing Behavior, TPF = Team Performance

Management teams are willing to facilitate knowledge-related transactive processes for improving knowledge sharing. Increasing organizational preparedness, accuracy of actions, creativity of sharing, and specialization are deeply constructed in management teams, followed by credibility and coordination, thus members can improve team performance. A direct relationship between knowledge-sharing behavior and performance is an important finding consistent with previous researches of Bunderson and Sutcliffe (2002) and Srivastava et al. (2006). Providing special expertise and promoting management teams to focus on knowledge-sharing behavior are the important improvements to achieve company goals. Team cohesion in the empowering leadership-performance relationship also appears to be required. The evidence of positive effects of empowering leadership on both team process and emergent states indicates the robustness of findings on empowering leadership in teams. The result shows that group cohesiveness is a strong predictor for the performance (Keller, 1986). The outcomes of this study require both practitioners and academicians to reconsider their attitudes on the subtle management of knowledge-sharing behavior. The literature findings may lead the analysts to recognize that measuring and managing knowledge-sharing behavior may become the most significant managerial activity to improve team performance.

\section{Conclusion}

The purposes of this study were to determine a practical framework and to create a causal model of empowering leadership, team cohesion, knowledge-sharing behavior, and team performance for petroleum refinery plant employees in Thailand. The findings show that the empowering leadership, team cohesion, and knowledge-sharing behavior have the strength to mediate positive effect on team performance. In relation to the practical framework and causal model, that is the extent to which dimensions of empowering leadership, team cohesion, and knowledge-sharing behavior have mediated positive effect on team performance. Knowledge-sharing behavior positively mediates the relationships between empowering leadership and team performance and between team cohesion and team performance. Furthermore, empowering leadership is positively correlated with team cohesion. Management team can expand knowledge of teams by developing shared understanding and collaboration, and connecting their actions with quick improvement to enhance team performance. This study draws special attention to team design in organizations. In order to promote knowledge-sharing behavior, besides considering other relevant organizational and individual factors, managers need to cultivate a nurturing team environment since team is the most proximal social context for individuals within which they frequently interact with peers (Fulk, 1993; Liang et al., 2010). Managers need to create cohesive and innovative teams in order to share knowledge with others due to normative pressures arising from the strong team cohesion and trust on peers. In addition, empowering leadership skills should be emphasized when selecting or evaluating team leaders.

The empowering leadership skills of current team leaders can be strengthened by improving each of the five components identified by Arnold et al. (2000), namely participating, decision making, informing, and showing concern. Appropriate training programs can be provided to help team leaders and teams members identify their weaknesses and develop their necessary skills to improve operational and managerial knowledge's and have great potential to reinforce employees' knowledge-sharing behavior and to enhance team performance. The motivational basis of team performance is an important component of the research agenda related to management practices. Examining the role of empowering leadership, team cohesion, and knowledge-sharing behavior on team performance, this study expands knowledge about organizational resources that foster willingness to dedicate efforts and abilities to a work task. Identifying empowering leadership and team cohesion as antecedents of knowledge-sharing behavior and team performance, this study also extends research in that domain, still in its early stages. An important theoretical contribution of this study is positioning knowledge-sharing behavior as a means through which job resources are linked to employee outcomes. Investigating the mediating role of knowledge-sharing behavior in the relationship among empowering leadership, team cohesion, and team performance, this study addresses a call to examine the mechanisms that operate between empowering leadership and team cohesion, and team performance. Finally, this study contributes in terms of organizational context. 
Recommendations: Before making interpretations on these findings, research limitations should be taken into account. First, there might have been some other factors that could affect knowledge-sharing behavior. These factors include demographic determinants such as age, gender, and natural barriers such as time and space (Bock et al., 2005). In this paper, the author did not study the effects of these potential factors; considering these factors in future researches can reveal their influences more clearly. Moreover, this study was carried out in Thai organizations with a relative collectivism culture; before any generalization is made, the culture influences must be taken into account. For further validity, this framework and causal model can be applied to samples in different countries or different cultures. In addition, the research sample was only consisted of operational employees in the petroleum refinery plants in Thailand; generalizations of research findings to different industries can provide more valuable findings about knowledge-sharing behavior and its enablers. Meanwhile it is noteworthy to mention that these findings are consistent with those of the studies carried out in countries in which cultures are characterized with high level of collectivism. Hence, the author suggests that the type of dominant culture might also be a factor that influences knowledge-sharing behavior and can be a topic for future researchers. Future research should replicate the findings of this study on outcomes to be measured through methods other than self-report. Since data were collected from manufacturing organizations in Thailand, the author cannot be sure of the generalizability of results to firms in other sectors or locations. However, these manufacturing organizations differed in terms of size, structure, and business goals, which diluted concerns of generalizability. Future studies should evaluate the model in diverse geographic and occupational settings to enhance the external validity. Finally, knowledge management can result in other organizational outcomes that can consequently lead to competitive advantage (Nonaka \& Takeuchi, 1995). Examining the influence of knowledge-sharing on other organizational outcomes such as business intelligence and organizational learning are among interesting themes for further studies.

\section{References}

Ahearne, M., Mathieu, J. \& Rapp, A. (2005). To empower or not to empower your sales force? An empirical examination of the influence of leadership empowerment behavior on customer satisfaction and performance. Academy of Applied Psychology, 90(5), 945-955.

Alavi, M. \& Leidner, D. (2001). Review: Knowledge management and knowledge management systems: Conceptual foundations and research issues. MIS Quarterly, 25(1), 107-136.

Amabile, T., Schatzel, E., Moneta, G. \& Kramer, S. (2004). Leader behaviors and the work environment for creativity: Perceived leader support. Leadership Quarterly, 15(1), 5-32.

Amy, E. (1999). Psychological safety and learning behavior in work teams. Administrative Science Quarterly, 44(2), 350-383.

Antonuccio, D. O., Davis, C., Lewinsohn, P. M. \& Breckenridge, J. L. (1987). Therapist variables related to cohesiveness in a group treatment for depression. Small Group Behavior, 18(4), 557-564.

Arnold, J. A., Arad, S., Rhoades, J. A. \& Drasgow, F. (2000). The empowering leadership questionnaire: The construction and validation of a new scale for measuring leader behaviors. Journal of Organizational Behavior, 21(3), 249-269.

Barrick, M. R., Bradley, B. H., Kristof-Brown, A. L. \& Colbert, A. E. (2002). The moderating role of top management team interdependence: Implications for real teams and working groups. Academy of Management Journal, 50(3), 544-557.

Beal, D. J., Cohen, R., Burke, M. J. \& McLendon, C. L. (2003). Cohesion and performance in groups: A meta-analytic clarification of construct relations. Journal of Applied Psychology, 88(6), 989-1004.

Bock, G., Zmud, R. W., Kim, Y. \& Lee, J. (2005). Behavioral intention formation in knowledge sharing: Examining the roles of extrinsic motivators, social-psychological forces, and organizational climate. MIS Quarterly, 29(1), 87-111.

Bunderson, J. S. \& Sutcliffe, K. M. (2002). Comparing alternative conceptualizations of functional diversity in management teams: Process and performance effects. Academy of Management Journal, 45(5), 875-893.

Carron, A. V. \& Brawley, L. R. (2000). Cohesion: Conceptual and measurement issues. Small Group Research, 31(1), 89-106.

Carron, A. V., Widmeyer, W. N. \& Brawley, L. R. (1985). The development of an instrument to measure cohesion in sport teams: The group environment questionnaire, Journal of Sport Psychology, 7(3), 244-266. 
Cummings, J. N. (2004). Work groups, structural diversity, and knowledge sharing in a global organization. Management Science, 50(3), 352-364.

Devine, D. J. \& Phillips, J. L. (2001). Do smarter teams do better? A meta-analysis of cognitive ability and team performance. Small Group Research, 32(5), 507-532.

Druskat, V. U. \& Wheeler, J. V. (2003). Managing from the boundary: The effective leadership of self-managing work teams. Academy of Management Journal, 46(4), 435-457.

Elron, E. (1997). Top management teams within multinational corporations: Effects of cultural heterogeneity. Leadership Quarterly, 8(4), 393-413.

Fulk, J. (1993). Social construction of communication technology. Academy of Management Journal, 36(5), 921-950.

Gold, A. H., Malhotra, A. \& Segars, A. H. (2001). Knowledge management: An organizational capabilities perspective. Journal of Management Information Systems, 18(1), 185-214.

Gully, S. M., Devine, D. J. \& Whitney, D. J. (1995). A meta-analysis of cohesion and performance: Effects of level of analysis and task interdependence. Small Group Research, 26(4), 497-520.

Hogg, M. A. (1992). The Social Psychology Group Cohesiveness: From Attraction to Social Identity. New York: New York University Press.

Joreskog, K. G. \& Sorbom, D. (1993). LISREL 8: User's Reference Guide. Chicago: Scientific Software International.

Kankanhalli, A., Tan, B. C. Y. \& Wei, K. K. (2005). Contributing knowledge to electronic knowledge repositories: An empirical Investigation, MIS Quarterly, 29(1), 113-143.

Katzenbach, J. R. \& Smith, D. K. (1993). The discipline of teams. Harvard Business Review, 71(2), 111-121.

Keller, R. T. (1986). Predictors of the performance of project groups in R\&D organizations. Academy of Management Journal, 29(4), 715-726.

Keyton, J. \& Springston, J. K. (1990). Redefining cohesiveness in groups. Small Group Research, 21(2), 234-254.

Lawler, E. J., Thye, S. R. \& Yoon, J. (2000). Emotion and group cohesion in productive exchange. American Journal of Sociology, 106(3), 616-657.

Liang, H., Saraf, N., Hu, Q. \& Xue, Y. (2007). Assimilation of enterprise systems: The effect of institutional pressures and the mediating role of top management. MIS Quarterly, 31(1), 59-87.

Liang, H., Xue, Y., Ke, W. \& Wei, K. (2010). Understanding the influence of team climate on IT use. Journal of the Association for Information Systems, 11(8), 414-432.

Littlepage, G. E., Cowart, L. \& Kerr, B. (1989). Relationships between group environment scales and group performance and cohesion. Small Group Research, 20(1), 50-61.

Marks, M. A., Mathieu, J. E. \& Zaccaro, S. J. (2001). A temporally based framework and taxonomy of team processes. Academy of Management Review, 26(3), 356-376.

Mathieu, J., Gilson, L. L. \& Rubby, T. M. (2006). Empowerment and team effectiveness: An empirical test of an integrated model. Journal of Applied Psychology, 91(1), 97-108.

Nahapiet, J. \& Ghoshal, S. (1998). Social capital, intellectual capital, and the organizational advantage. Academy of Management Review, 23(2), 242-266.

Nonaka, I. \& Takeuchi, H. (1995). The Knowledge-Creating Company: How Japanese Companies Create the Dynamics of Innovation. New York: Oxford University Press.

O'Reilly, C., Caldwell, D. \& Barnett, W. (1989). Work group demography, social integration and turnover. Administrative Science Quarterly, 34(1), 21-38.

Pavlou, P. A., Liang, H. \& Xue, Y. (2007). Understanding and mitigating uncertainty in online exchange relationships: A principal-agent perspective. MIS Quarterly, 31(1), 105-136.

Peccei, R., \& Rosenthal, P. (2001). Delivering customer-oriented behavior through empowerment and turnover. Administrative Science Quarterly, 38(6), 831-857.

Reid, F. (2003). Creating a knowledge sharing culture among diverse business units, Employment Relations Today, 30(3), 43-49.

Robertson, S. (2002). A tale of two knowledge-sharing systems, Journal of Knowledge Management, 6(3), 295-308.

Senge, P. (1997). Sharing knowledge: The leader's role is key to a learning culture. Executive Excellence, 
4(11), 17-18.

Shaw, M. E. (1981). Group Dynamics: The Psychology of Small Group Behavior. New York: McGraw-Hill.

Siemsen, E., Roth, A. \& Balasubramanian, S. (2008). How motivation, opportunity, and ability drive knowledge sharing: The constraining-factor model. Journal of Operations Management, 26(3), 426-445.

Sigler, T. H. \& Pearson, C. M. (2000). Creating an empowering culture: Examining the relationship between organizational culture and perceptions of empowerment. Journal of Quality Management, $5(1), 27-52$.

Simsek, Z., Veiga, J. F., Lubatkin, M. \& Dino, R. (2005). Modeling the multilevel determinants of top team management behavioral integration. Academy of Management Journal, 48(1), 69-84.

Smith-Jentsch, K. A., Mathieu, J. E. \& Kraiger, K. (2005). Investigating linear and interactive effects of shared mental models on safety and efficiency in a field setting. Journal of Applied Psychology, 90(3), 523-535.

Srivastava, A., Bartol, K. M. \& Locke, E. A. (2006). Empowering leadership in management teams: Effects on knowledge sharing, efficacy, and performance. Academy of Management Journal, 49(6), 1239-1251.

Stasser, G. \& Titus, W. (1985). Pooling of unshared information in group decision making biased information sampling during discussion. Journal of Personality and Social Psychology, 48(6), 1467-1478.

Teece, D. J. (1998). Capturing value from knowledge assets: The new economy, markets for know-how, and intangible assets. California Management Review, 40(3), 55-79.

Yalom, I. D. (1995). The Theory and Practice of Group Psychotherapy. New York: Basic Books.

Yamane, T. (1970). Statistics - An Introductory Analysis. Tokyo: John Weatherhill.

Zhang, X. \& Bartol, K. M. (2010). Linking empowering leadership and employee creativity: The influence of psychological empowerment, intrinsic motivation, and creative process engagement. Academy of Management Journal, 53(1), 107-128. 